\title{
GUARDA COMPARTILHADA: UM DIREITO DA CRIANÇA A PARTIR DAS NOVAS FORMATAÇÕES FAMILIARES
}

\author{
Flávia Leite do Rêgo Barros ${ }^{1}$ \\ Elias Gonçalves Silva ${ }^{2}$ \\ Myller Vicente de Freitas ${ }^{3}$ \\ Diógenes José Gusmão Coutinho ${ }^{4}$
}

\begin{abstract}
RESUMO: A discussão acerca do instituto da guarda compartilhada tem na adição das novas formatações familiares um produto social que tem avolumado as demandas jurídicas. As idiossincrasias próprias destas novas configurações afetivas exigem, também, sentenciamentos jurídicos que acolham as demandas destes grupos após a ruptura das relações afetivas pautadas nas mais diversas formatações familiares. È exigido do Direito de família a resposta coerente e equilibrada que satisfaçam as demandas destas novas conjugações familiares que se apartem do antigo modelo de família. Para tanto, a discussão aqui se centra no direito basilar das crianças menores a convivência harmoniosa, constante e profícua e com seus genitores garantindo a manutenção dos laços de afeto entre as partes, após a dissolução do matrimônio. É explanado acerca das novas formatações familiares acolhidas pela normativa jurídica brasileira a partir do apanhado histórico que fornece elementos que permite vislumbrar os caminhos trilhados pelo instituto da família a partir do arcabouço jurídico brasileiro. A pesquisa qualitativa foi eleita para nortear o trabalho no que concerne os aspectos metodológicos. Este estudo é fundamentalmente pautado na pesquisa bibliográfica que trará a baila um breve apanhado histórico acerca do direito civil no Brasil e, simultaneamente, a utilização dos documentos legais que darão o suporte teórico necessário para situar a legislação brasileira acerca dos
\end{abstract}

\footnotetext{
${ }^{1}$ Bacharel em Direito pela Universidade Salgado de Oliveira- UNIVERSO e graduada em Licenciatura Plena em História pela FAINTIVISA, especialista em História do Brasil pela FAINTIVISA, Gestão Escolar e Coordenação Pedagógica pela faculdade ALPHA, Especialização em Pesquisa Avançada pela Faculdade ALPHA e mestranda em Ciências Jurídicas pela Atenas College University - Estados Unidos. Email: flaviarego@bol.com.br.
}

${ }^{2}$ Graduado em Direito pelo Instituto Pernambucano de Ensino Superior- IPESU , Especialização em Pesquisa Avançada pela Faaculdade ALPHA e aluno regular do Programa de Mestrado em Direito pela Atenas College University - Estados Unidos. .E-mail: eliasgonçalves@ hotmail.com.

${ }^{3}$ Graduado em Direito pelo Instituto Pernambucano de Ensino Superior- IPESU, Especialista em Direito e Processo Civil pela Faculdade Joaquim Nabuco , Especialista em Pesquisa Avançada pela Faculdade ALPHA e aluno regular do Programa de Mestrado em Direito pela Atenas College University- Estados Unidos. . E-mail: myllervicente@yahoo.com.br.

${ }^{4}$ Graduado em Biologia Pela Universidade Federal Rural de Pernambuco (UFRPE), Doutor em Biologia pela Universidade Federal de Pernambuco e Professor e Coordenador do Curso de Mestrado em Direito Pela Faculdade ALPHA - Atenas College University - Estados Unidos. E-mail.: alphadiogenes@gmail.com 


\title{
Universidade do Extremo Sul Catarinense \\ Revista Ibero-Americana de Humanidades, Ciências e \\ Educação \\ UneSC Produção e democratização do conhecimento na lbero-América
}

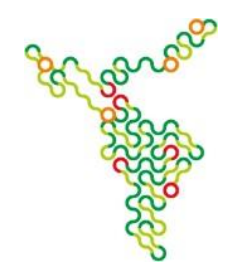

direitos dos filhos diante da conjugação matrimonial dos pais.

Palavras-chave: Guarda Compartilhada. Legislação brasileira. Direito da Criança. Famílias Plurais.

\section{JOINT CUSTODY: A CHILD RIGHT FROM THE NEW FAMILY FORMATTING}

\begin{abstract}
The discussion about the institute of joint custody has in addition of the new family formatting a social item which has enlarge legal demands. The own idiosyncrasy of these new affective settings requires, too, legal sentencing which granted the demands of these groups after the rupture of emotional relationships grounded in various familiar formatting. It is required of family law, consistent and balanced answers that satisfy the demands of these new Family combination that break with the old family model. For this purpose, the discussion here focuses on the Basic Law to minor children to a harmonious coexistence, constant and fruitful with their parents by ensuring the maintenance of the bonds of affection between the parties, after the marriage dissolution. It is outlined about the new family formatting endorsed by the Brazilian legal regulations from a historical overview that provides elements that allow a glimpse of the beaten paths by the Family Institute from Brazilian legal framework. The qualitative research was elected to guide the work on methodological aspects. This study is fundamentally based on literature search that will bring up a brief history about the civil law caught in Brazil and, concurrently, the use of legal documents that will provide the necessary theoretical support to situate the legislation about the rights of Brazilian children in front of their parents ' marital conjugation.
\end{abstract}

Key words: Joint Custody. Brazilian Legislation. Children's Rights. Plural Families.

\section{INTRODUÇÃO}

Vivendo o momento histórico, também, conceituado de modernidade líquida, em que a rapidez em que ocorrem as vias de comunicação entre os sujeitos se estreitaram e ganharam uma rapidez nunca vista, trouxe também, outro fenômeno em que a qualidade dos elos sentimentais se fragilizou e, como produto, tem prazo de validade, são exauríveis e descartáveis. Dentro desta conjuntura, situam-se as relações paternas- filiais imbricadas nesta atmosfera de fragilidade dos vínculos afetivos firmados entre os indivíduos. Diante deste contexto social, se insere essa discussão acerca das responsabilidades parentais perante os filhos menores.

As demandas sociais urgenciam posicionamentos do direito de família é neste contexto que este artigo se escreve, e nomeia a guarda compartilhada como um direito da criança à convivência salutar e harmoniosa com os seus genitores. 


\section{Universidade do Extremo Sul Catarinense \\ Revista Ibero-Americana de Humanidades, Ciências e \\ Educação \\ unesc \\ Produção e democratização do conhecimento na lbero-América}

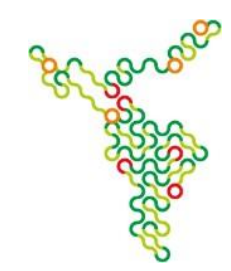

Novas requisições se apresentam ao direito, e se elevam a partir dos diversos arranjos familiares que rompem com o modelo de família tradicional. O grande leque de configurações socioafetiva exige novas formatações jurídicas que respondam convenientemente as novas demandas sociais. Sendo assim, ao direito cabe responder efetivamente aos pleitos sociais tendo o cuidadoso olhar acerca do melhor interesse da criança

no atendimento a garantia de convivência e manutenção dos seus laços de afeto com os seus progenitores.

Ao direito de família urge encontrar alternativas legais que espelhem o universo factual ao qual está inserido. Hoje, a guarda compartilhada se esmera em oferecer a ferramenta jurídica que permita aos pais a convivência igualitária à vida dos seus filhos após a ruptura das suas relações matrimoniais. No entanto, o viés jurídico indica aos genitores a titularidade das obrigações e direitos, mas indubitavelmente recai ao genitor guardião físico a responsabilidade no gerenciamento da vida dos filhos menores.

O esquema de visitas que deveria funcionar somente como um arranjo necessário a garantia da rotina da criança em um dos domicílios, traz a falsa ideia de minoração das responsabilidades ao genitor visitante diante das demandas inerentes a vida cotidiana dos seus filhos.

A garantia jurídica ao direito de visitas é, sobretudo, o direito do menor em gozar da convivência contínua que garanta a manutenção do elo afetivo entre os filhos e o genitor visitante. E que a ruptura conjugal não fragilize as relações paternas afetivas ou como comumente se observa, a visita estanques em que a participação do genitor na vida dos seus filhos se limite ao tempo do encontro entre os pais e filhos.

O Direito é intolerável no que se refere ao prejuízo moral, assim, qualquer ação que cause danos, gera responsabilidade, ou seja, há necessidade de se reparar tal dano. No entanto, é imperativo que o Direito de família se esmere em referendar as especificidades da guarda compartilhada na ação de participação equidosa dos genitores na vida dos seus filhos de modo a minorar as ações danosas causadas pela ruptura dos laços afetivos entre pais e filhos após a separação matrimonial.

\section{O PAPEL HISTORICAMENTE DESEMPENHADO PELA FAMÍLIA NO ORDENAMENTO PÁTRIO}

Entendendo a família como uma constituição histórica, que tem a sua gênese 


\section{Universidade do Extremo Sul Catarinense \\ Revista lbero-Americana de Humanidades, Ciências e \\ Educação \\ unesc

profundamente ligada a evolução da humanidade e que, por conseguinte, ilustra através da sua dinâmica de funcionamento das concepções e preceitos que norteiam as práticas de ordem sócio - culturais de um dado momento histórico e temporal. Sendo assim, é plausível afirmar que a atenção às garantias do direito da família está intimamente ligada à evolução social.

Um apanhado histórico acerca da definição de família no ordenamento jurídico brasileiro percebe-se uma nítida mudança acerca do olhar do direito sobre o instituto familiar para os sujeitos do núcleo familiar.

No espaço temporal compreendido entre o período colonial até 1916, data que o Brasil ganhou seu primeiro Código Civil, as leis que ditavam as relações de ordem jurídica no país eram de origem portuguesa. Inicialmente as Ordenações Afonsinas trouxeram seus ditames para o solo brasileiro e rapidamente foi substituído pelas Ordenações Manuelinas5, este documento datado no ano de 1520 bem próximos ao registro oficial do nascimento do Brasil que e finalmente as Ordenações Filipinas6 que foi amplamente usada no país até ser estabelecido no Brasil à República em 1822. O 4. ${ }^{\circ}$ Livro desta última Ordenação portuguesa trazia as normatizações sobre as famílias com seus direitos e limites de atuação, inclusive, tratando sobre o direito sucessório dentro do núcleo familiar da época.

Neste documento, a origem da família se dava exclusivamente pela constituição do casamento, e que, o homem era o único donatário dos desígnios familiar, inclusive, sendo o representante legítimo da esposa, já que nesta época, era considerada inábil para lidar com os atos próprios da engrenagem social. Este documento concedia ao marido a permissão para assassinar a esposa, tida como adúltera.

Havia uma clara categorização dos filhos na Ordenação Filipina, e dividia-se em três classes estanques, a saber:

\footnotetext{
5 "As Ordenações Manuelinas (1514- 1603), foi determinada pela existência de vultoso número de leis e atos modificadores das Ordenações Afonsinas. Foram compiladas no reinado de Dom Manuel I." (NASCIMENTO, F. L. do. A transformação do conceito de família no âmbito jurídico. Salvador: Ucsal, 2009). (Dissertação/Mestrado) (BDTD).

6 "Ordenações Filipinas, que surgiram como resultado do domínio castelhano. Ficaram prontas ainda durante o reinado de Filipe I, em 1595, mas entraram efetivamente em vigor em 1603, no período de governo de Filipe II. Foram sendo paulatinamente revogados, mas substituídos por textos que, de certa forma, mantinham suas influências". (NASCIMENTO, F. L. do. A transformação do conceito de família no âmbito jurídico. Salvador: Ucsal, 2019). (Dissertação/Mestrado) (BDTD).
} 


\section{Universidade do Extremo Sul Catarinense \\ Revista Ibero-Americana de Humanidades, Ciências e \\ Educação \\ unesc

Legítimo - Nascidos após a contratação do casamento; legitimado- Aquele concebido anterior ao casamento, mas que posteriormente os pais casaram-se e os filhos foram convalidados com a união conjugal e ilegítimos ${ }^{6}$ - frutos de relacionamentos alheios ao casamento dos pais por diversos motivos, entre eles: consanguinidade, voto religioso e casamento.

Essas condições descritas eram os parâmetros usados pela lei vigente na época para emoldurar as relações familiares baseadas no acordo jurídico entre os pais que privilegiava a manutenção do status familiar em detrimento aos direitos dos filhos frutos do casamento ou não.(NASCIMENTO, 2016, p. 397)

Os filhos legítimos e legitimados eram subjugados ao pátrio poder, nesta época, exercido exclusivamente pelo genitor. Aos filhos era delegada a condição de completa submissão aos ditames paternos por tempo indeterminado, já que o pátrio poder não cessava com a exclusiva condição deste filho aos 21 anos.

Aos filhos nascidos da estrutura matrimonial, segundo PEREIRA (2017, p. 30), não gozavam da autoridade do pai, "era a mãe quem exercia os direitos e deveres decorrentes da filiação, o denominado poder materno, nomeando-se tutor apenas no caso da genitora ser desconhecida ou incapaz de exerce- lá."

Essas leis que amparavam o direito da família no período colonial cessaram após a promulgação do Código Civil em 1916 que trouxe a novidade do reconhecimento do casamento civil pelo Estado, destinando o enlace matrimonial de cunho religioso como um acessório particular, mantendo as suas características indissolúveis por ser considerada, na época, uma obra sagrada.

O Código Civil mantinha inalterado o pátrio poder paterno e a segurança jurídica da família em prejuízo aos direitos individuais dos seus membros. E sobre "os filhos menores, prévia, o artigo 384 do Código Civil de 1916 que aos pais cabia crialos e educa- lós, tê-los em sua companhia e guarda". VELOSO, (2016, p. 496)

A Constituição de 1934 inaugurou o marco que confere ao Estado o dever de proteger o instituto da família. Sendo que a intervenção estatal se refere ao nicho familiar dentro da roupagem trazida pelo Código Civil de 1916 em que trata da indissolubilidade do casamento, e ainda, trata o instituto da família com base na sua origem advinda da união conjugal, mais uma vez, negligenciando os direitos dos filhos concebidos paralelamente ao casamento. 

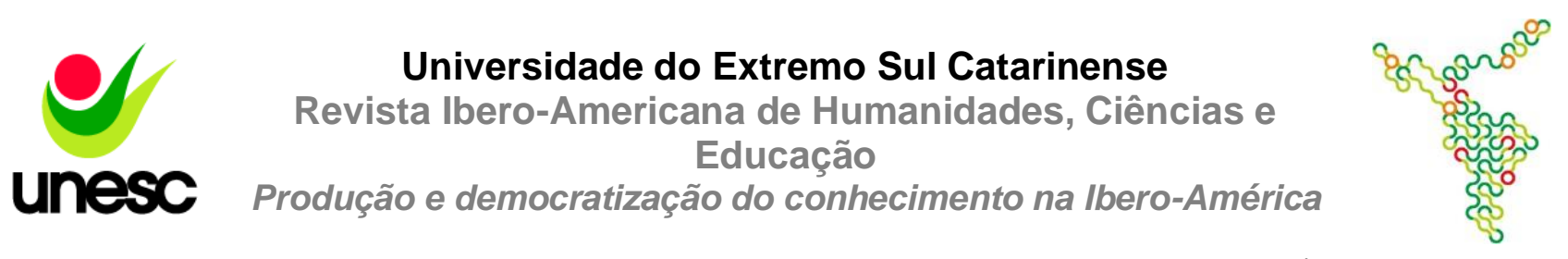

2.1 O MENOR COMO DETENTOR DE DIREITOS NO SEIO FAMÍLIA

Essa perspectiva permite situar a responsabilidade dos genitores. Podendo separar em dois aspectos, os inúmeros deveres que os pais possuem no que se refere a vida dos seus filhos: o dever da assistência e o dever da vigilância.

Nesse contexto, duas responsabilidades dos pais são decorridas: uma oriunda dos atos realizados pelos próprios pais durante a criação dos menores e o segundo, proveniente das ações realizadas pelos filhos como menor idade.

No que se refere as responsabilidades provenientes dos atos realizados pelos pais

e partindo da premissa "que às crianças são reflexos do meio onde vivem, são reflexo s dos pais, a responsabilização dos pais por desacertos na criação e educação de seus filhos torna-se inegável.” BARBOZA, (2018, p. 30)

Assim, o artigo 384 do código civil determina nos seus incisos I e II que compete aos pais, quanto à pessoa dos filhos menores que lhes dirija a criação e educação, além de tê-los em sua companhia e guarda. Ainda, o código civil estabelece no artigo 231, inciso IV, a responsabilidade dos cônjuges quanto ao sustento, guarda e educação dos filhos. Caso ocorra o descumprimento desses deveres, os pais serão submetidos ao artigo 159 do Código Civil que determina: "Aquele que, por ação ou omissão voluntária, negligência, ou imprudência, violar direito, ou causar prejuízo a outrem, fica obrigado a reparar o dano". Vale salientar que, tal reparo não possui relação com o direito a alimento do menor.

\subsection{PREPONDERÂNCIA SOBRE O MELHOR INTERESSE DA CRIANÇA}

As citações iniciais sobre o melhor interesse a criança datam do período a monarquia inglesa, no século XIV, em que cabia ao rei a tutela das crianças que não podiam gerenciar sua inserção social, assim como, fazer uso dos bens que essa criança tinha atrelado ao seu nome. A partir e 1836 que a corte inglesa começou a considerar o melhor interesse do menor em detrimento aos ditames o Estado inglês.

Somente a partir de 1924 é que os organismos internacionais começaram a se debruçar sobre tratados que trouxesse nas suas linhas as garantias da prerrogativa do interesse o menor como preocupação, inclusive dando um tratamento especial no tocante a esses interesses. Assim ocorreu na Declaração de Genebra em 1924 e 


\section{Universidade do Extremo Sul Catarinense \\ Revista lbero-Americana de Humanidades, Ciências e \\ Educação \\ unesc

posteriormente em 1948 com a Declaração dos Direitos Humanos. Já em 1989 esses direitos foram referendados e ampliados na Convenção sobre os Direitos da Criança, abonada pela Organização as Nações Unidas e que foi confirmada pelo Brasil ao sancionar o Decreto $\mathrm{n}^{\circ}$ 99.710/90 que referendou na legislatura brasileira a proteção integral e garantias que prevalecesse a tutela especial dos menores previstos nas normativas internacionais.

Endossando este posicionamento é possível afiançar que:

Foram reconhecidos no âmbito internacional, direitos próprios da criança [...] Nessa Linha, passa a criança a ter direitos à vida, a um nome, à nacionalidade, a preservar a sua identidade, à liberdade de expressão e opinião- devendo ser ouvida em todo processo judicial que lhe diga respeito- à liberdade de pensamento, consciência, de crença, de associação: enfim, tem reconhecidamente dignidade inerente e os direitos iguais e inalienáveis de todos os membros da família humana. (BARBOZA, 2018, p. 30)

Sendo que antecipadamente, a Constituição Federal de 1988, inaugurou no ordenamento pátrio as prerrogativas sobre os direitos intrínsecos ao amparo das crianças menores e dos adolescentes. $\mathrm{O}$ art. 227 da C.F traz um novo olhar acerca do conceito de família que põe a pique o modelo patriarcal e autoritário, dando lugar para a ideia e família pautada pelo ideário de dignidade, afeto e solidariedade entre os seus membros. Nesta perspectiva a criança e o adolescente ganham o status diferenciado e especial, em que os pais devem garantir o seu pleno desenvolvimento integral.

A nova formatação legislativa também impõe a sociedade e ao Estado, responsabilidades no tocante a garantia dos direitos fundamentais das crianças e dos adolescentes. Os novos contornos legislativos exigem de todos a constante observância das premissas fundamentais que garantam a efetivo amparo das crianças e adolescentes diante da sua vulnerabilidade. Neste sentido é asseverado que "[...] sempre que os interesses ou os direitos da criança e do adolescente colidirem com os de seus pais, ou de terceiros, dever-se-á atender ao princípio do superior interesse o menor.” DINIZ, (2018. p. 203)

\subsection{FAMÍLIAS PLURAIS E SOLIDARIEDADE FAMILIAR}

A Carta Magna garante três institutos familiares, ditos: a união estável, o casamento e a família monoparental que é composta por um dos genitores e a prole. Com a ressignificação do conceito de família, a revisão constitucional destas três entidades é meramente exemplificativa, já que, a égide da Lei Maior é a equidade entre 


\title{
Universidade do Extremo Sul Catarinense \\ Revista Ibero-Americana de Humanidades, Ciências e \\ Educação \\ unesc

todos os sujeitos, sendo assim, todas as formatações familiares merecem o acolhimento do Estado para que seja garantida a dignidade dos partícipes destes diversos núcleos familiares.

\begin{abstract}
Ao suprimir a locução constituída pelo casamento (art.175 da Constituição de 1967/1969), sem substituí-la por qualquer outra, pôs sob a tutela constitucional a família, ou seja, qualquer família constituída socialmente. A cláusula de exclusão desapareceu. O fato de, em seus parágrafos, referir a tipos determinados, para atribuir-lhes certas consequências jurídicas, não significa que restituiu a cláusula de exclusão, como se ali estivesse à locução a família constituída pelo casamento, pela união estável ou pela comunidade ormatada por qualquer dos pais e seus filhos. A interpretação de uma norma ampla não pode suprimir de seus efeitos, situações e tipos comuns, restringindo direitos subjetivos. (LOBO, 2018, p. 58)
\end{abstract}

\subsection{IGUALDADE E AFETIVIDADE}

No século XVI até XIX a legislação brasileira não aventava as premissas que tratavam do caráter igualitário entre os seus membros, fica patente a inexequibilidade deste princípio diante de uma sociedade patriarcal e fundamentada em hierarquia entre seus componentes. E a concepção de afeto era bem distanciada dos moldes percebidos na atualidade.

Hoje o arcabouço jurídico brasileiro, no tocante ao direito e família, adjudica aos filhos, tratamento equipolente e a Constituição cidadã no seu artigo 227, assevera $\S$ 6. "Os filhos, havidos ou não da relação do casamento, ou por adoção, terão os mesmos direitos e qualificações, proibidas quaisquer designações discriminatórias relativas à filiação". Assim, fica vedado o tratamento desigual entre os filhos.

Pode- se inferir que do princípio a igualdade, nasce da afetividade como substrato da união familiar. Com a legitimidade da igualdade entre os filhos, cabe aos pais dar tratamento sob a égide do afeto a todos os filhos, independente da sua procedência genética ou conexão jurídica. Garantindo assim, um pleno desenvolvimento psicossocial da sua filiação.

Acerca do princípio da igualdade no trato com os filhos são abreviados:

Ambos os pais, casados ou não, passam a ter papel semelhante na educação dos filhos, desaparecendo a autoridade exclusivamente marital. A família, doravante, deve gravitar em torno de um vínculo de afeto, de recíproca compreensão e mútua cooperação (...). A família passa a ter um conteúdo marcadamente ético e cooperativo e não mais econômico resquício esse da velha família romana e, nesse contexto, não há espaço para qualquer discriminação. Sob tal prisma. (VENOSA, 2014, p. 226) 


\section{Universidade do Extremo Sul Catarinense \\ Revista Ibero-Americana de Humanidades, Ciências e \\ Educação \\ Produção e democratização do conhecimento na lbero-América}

unesc

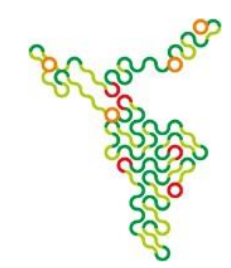

Desta forma há uma divisão equânime entre os genitores sobre o gerenciamento da vida cotidiana dos seus filhos. Essa condição, garantida por lei não se limita ao dever se alimentar e criar agrega, ainda, o vínculo afetivo entre pais e filhos como lastro basilar para garantir a saúde psicoemocional da prole.

\subsection{AS POSSIBILIDADES JURÍDICAS PARA A GUARDA DOS FILHOS APÓS DISSOLUÇÃO7 DAS ENTIDADES FAMILIARES}

Uma das questões que mais gera discussões e motivos de litígios ao final de um relacionamento afetivo é o instituto da guarda dos filhos frutos dessa relação. Ao se falar em guarda o seu conceito transcende a ideia usual de convivência diária com o menor. A guarda pode ter um viés transitório e parcial, ou ainda partilhado. Cabendo ao genitor desempenhar a sua competência parental sobre o menor a qual the foi conferido a guarda. E ao genitor não guardião cabe à obrigação de velar pelo interesse do filho menor.

O enxerto abaixo corrobora com tal afirmação ao dizer que:

Quando se fala em guarda, o que nos vem à mente é uma relação de companhia permanente, ou seja, de alguém que viva com outra pessoa na mesma residência e dela dependa, em vários aspectos, para a sua subsistência. Esta é o guardião que deve prestar ao que está sob sua guarda, assegurando-lhe tudo aquilo que é necessário para o pleno desenvolvimento da sua personalidade. (ELIAS, 2009, p. 47)

A Normativa Civil em seu art. 1.631, diz: durante o casamento e a união estável, compete o poder familiar aos pais; na falta ou impedimento de um deles, o outro o exercerá com exclusividade.

O Código Civil de 2002 corrobora com o enxerto anterior quando afirma que: Art. 1.632. A separação judicial, o divórcio e a dissolução da união estável não alteram as relações entre pais e filhos senão quanto ao direito, que aos primeiros cabe, de terem em sua companhia os segundos.

Sendo assim, fica aponto que o poder familiar desempenhado pelos pais permanece imperturbado, ainda que, não compartilhe o mesmo lócus de habitação com

\footnotetext{
${ }^{7}$ É de suma importância situar a ideia de "dissolução da entidade familiar" como a ruptura da relação afetiva entre os genitores, assim como, a separação judicial, o divórcio, a união de caráter estável e/ou outra na qual exista a coabitação dos menores com os seus pais. $4 \mathrm{O}$ art. 1.590 do Código Civil, trata "as disposições relativas à guarda e prestação de alimentos aos filhos menores estendem-se aos maiores capazes”.
} 


\section{Universidade do Extremo Sul Catarinense \\ Revista Ibero-Americana de Humanidades, Ciências e \\ Educação \\ unesc

o menor, ou ainda, coabite com esses menores em períodos predefinidos 8 judicialmente ou por acordos firmados entre os genitores.

É valido ressaltar que o Código Civil brasileiro trata a guarda como um dos itens do cabedal de caracteres que compõe o poder familiar, mas que, em si, não constitui o dito poder familiar.

[...] cumpre observar que a guarda, tal como é tratada na lei civil, é um dos atributos do poder familiar, com ele não se confundindo. Além da guarda, o poder familiar consiste noutras prerrogativas, como a de direção da educação (art. 1.634, inc. I), de representação e assistência para os atos da vida civil (inc. IV), de exigência de respeito e obediência (inc. VII), etc. Tais prerrogativas, que não a guarda, subsistem também para o genitor nãoguardião, que, contudo, possui o direito de visitar os filhos e de tê-los em sua companhia, conforme determina o art. 1.589 do Código Civil. (TEIXEIRA, 2019, p. 36)

Por outro lado, existe no imaginário coletivo a ideia de que o genitor que detém a guarda do menor tem poderes irrestritos sobre este menor. Esse juízo, inclusive, pode se perpetuar por conivência ou por desconhecimento, na reminiscência do não individuo não guardião, corroborando assim para inadequado convívio familiar entre não guardião e menor.

Costumeiramente, a guarda é intendida pelo genitor que a detém como símbolo de poder familiar absoluto. Não é raro que o outro acompanhe esse pensamento. Não raro, também, a visita é tida como de caráter social, existindo apenas para que os filhos não deixem de ter contato com o genitor que mora em outra casa, È comum à visita ser utilizada como momentos de lazer e de prazer, maneira amorosa, complementada pela execução serena do regime de visitas, é que proporciona equilíbrio emocional aos filhos. A guarda existe para que a criança tenha domicílio e tenha definido o nome de quem assume os compromissos diuturnamente em relação a ela. O genitor visitador tem a fiscalização dos cuidados inerentes à guarda e à educação. Em famílias separadas, para sentir-se estável, a criança precisa ter sentimentos de dupla pertinência, isto é, saber que pertence inteiramente a suas duas.

Famílias (...). A criança precisa sentir que suas duas famílias são famílias inteiras, e precisa sentir, quando em estada do não guardião, que não é hóspede, mas filho pertencente à casa daquele. (TEIXEIRA, 2019, p. 39)

Diante do exposto, fica evidenciado que a guarda tem o papel de definir o intricado mix de obrigações e direitos dos genitores, mas que, deve ser comum a ambos os pais, sendo resguardado o amparo integral do menor. E esse animus deve está alçado em um patamar que deve transcender as desavenças de pleito ligadas a conjugalidade. Mas anterior ao exame dos predicados individuais, o estatuto do melhor interesse da

\footnotetext{
${ }^{8}$ Casos de guarda compartilhada
} 


\section{Universidade do Extremo Sul Catarinense \\ Revista Ibero-Americana de Humanidades, Ciências e \\ Educação \\ unesc

criança envolvido na disputa deve ser analisado obrigatoriamente, e em casos que o juiz sinta-se imperito ao julgamento, será feito um estudo com uma equipe multidisciplinar9 de modo a garantir o estatuto exposto acima Cada pedido de guarda remeterá o magistrado a diferenciar o genitor que acomode as melhores condições, sobretudo de ordem afetuosa, éticas e que dispunha de tempo necessário para zelar pela saúde biopsicossocial do menor. Não descartando, a aproximação afetiva que os filhos tenham com um dos genitores por conta de inúmeros fatores, entre eles: pouca idade da criança que geralmente tem um apego maior a mãe e/ou pouca convivência com os pais por conta dos compromissos profissionais do mesmo. $\mathrm{O}$ apego se dá aqueles que cuidam e dispõe de maior tempo para ter com esse menor.

Ao contrário dos adultos, crianças não possuem uma concepção psicológica de relações decorrentes de laços sanguíneos antes de um estágio avançado no seu desenvolvimento. Para os pais biológicos, a experiência de conceber e dar à luz os prepara para que se sintam mais próximos e responsáveis em relação aos seus filhos. Tais aspectos não produzem efeito nas crianças, que são emocionalmente alheias aos eventos que levaram à sua existência. $\mathrm{O}$ que importa para elas é o padrão do intercambio diário com os adultos que delas tomam conta e que, na força de tais interações, se tornam as figuras parentais a quem elas se apegam. (GOLDSTEIN,2010, p. 09)

Outros itens que exigem um olhar aguçado do magistrado se referem à conduta moral e equilíbrio psicológico dos genitores que pleiteiam a guarda do menor Há uma recomenda a observação de itens abaixo para dissuadir ao pleito da guarda. São eles:

Uso habitual de drogas, alcoolismo, maus- tratos, agressividade e descontrole emocional são fatores que desaconselham à atribuição da guarda e recomendam sua perda;

A guarda deve ser atribuída preferencialmente à pessoa (seja a mãe, pai, avós ou outros) com quem a criança se encontra, sendo maior a preferência quanto maior for o tempo de lidar com as mudanças, estas devem ser evitadas o quanto possível;

Desde em que as crianças se tornam aptas a expressar a sua vontade (...), a guarda deverá ser decidida de acordo com a opção da criança, salvo no caso de algum motivo recomendando a solução contrária, revelado pelos laudos social e psicológico;

Quando os filhos em idade pouco avançada, registra-se uma preferência pela mãe: todavia, cresce a tendência de superação dessa prioridade pelo critério segundo o qual a guarda deve ser atribuída preferencialmente ao genitor que exerça as "funções maternas", seja ele o pai ou a mãe. (LAURIA, 2019, p. 79)

A intenção com os itens elencados acima não é esgotar as possibilidades de análise da melhor condição para o menor e sim trazer a tona as situações mais

\footnotetext{
${ }^{9}$ Psicólogos, pedagogos, psiquiatras, assistente social, e outros que se fizerem necessários diante das demandas apresentadas por cada caso de pedido de guarda de menores.
} 


\title{
Universidade do Extremo Sul Catarinense \\ Revista lbero-Americana de Humanidades, Ciências e \\ Educação \\ unesc

corriqueiras observadas pela magistratura no julgamento das ações nas varas de família no Brasil e permitir uma discussão acerca do uso do instrumento da guarda compartilhada como item fragilizador da alienação parental, tão comum nos casos de pleito de guarda de crianças menores e adolescentes.

\subsection{GUARDA COMPARTILHADA}

Essa modalidade de guarda é contemplada Código Civil e se tornou uma categoria primaz utilizada pelos juízes e que é estimulada a serem adotadas pelos pais de maneira cordata. O juiz avaliza as condições da guarda da prole e que haja uma possibilidade de negociação amigável entre os genitores que garantam a possibilidade de diálogo entre eles na condução da melhor condição na educação dos filhos. Diante deste cenário, o magistrado opta pela guarda compartilhada como a melhor opção para a criança e institui a possibilidade de diminuição da condição da alienação parental já que convívio do menor com os dois genitores fragiliza a perpetuação do assédio, quando não, permite uma identificação prematura das situacionais definidas como condutas assediadoras.

Acompanhando os pressupostos do jurista é dito que a condição de guarda compartilhada segundo diz:

\begin{abstract}
Que surgiu de duas considerações bem nítidas: o desequilíbrio dos direitos parentais, que se tornou uma medida anacrônica, e de uma cultura que desloca o centro de seu interesse sobre a criança em uma sociedade de tendência igualitária. È de suma importância se deter acerca do conceito deste instituto e a sua função no cumprimento da análise da melhor condição para o menor. (LEITE, 2011, p. 262)
\end{abstract}

Na guarda compartilhada o tempo de convívio com os filhos devem ser dividido de forma equilibrada com o pai e a mãe, sempre tendo em vista as condições fáticas e os interesses dos filhos.

O artigo 1.583 do Código Civil define a corresponsabilização entre os pais para garantir a prática dos deveres e direitos que pertence aos pais que não coabitam o mesmo domicílio. Os pais resolvem consensualmente ou por definição judicial, repartirem o poder familiar em melhor condição integral da sua prole.

No art. 1.632 do Código Civil é explicito ao estabelecer que, separando-se o casal, em nada alteram suas relações entre filhos comuns. "Salvo quanto ao direito que nos primeiros cabe de terem a sua companhia os segundos". È dizer, o poder familiar dos genitores não se altera, a não ser, para o genitor não guardião, quanto à prerrogativa de ter os filhos em sua guarda e 
Universidade do Extremo Sul Catarinense

Revista Ibero-Americana de Humanidades, Ciências e

Educação

Produção e democratização do conhecimento na lbero-América

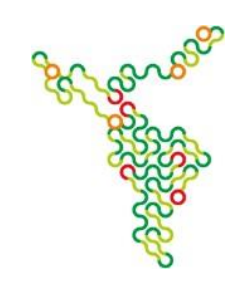

companhia (art. 1.634 II).

$[\ldots]$

Portanto, pode-se considerar que a grande alteração que a guarda compartilhada trouxe ao ordenamento brasileiro no que se refere ao exercício do poder familiar sobre os filhos menores, após a separação do casal, é esse: permitir o exercício conjunto do poder familiar pelos genitores, em sua totalidade, não fazendo ressalva, como ocorre na guarda unilateral, quanto ao direito de qualquer um dos genitores ter os filhos em sua companhia e guarda. Afinal, tal restrição é a única imposta ao poder familiar do genitor, que na guarda unilateral a detém. (LEITE, 2011, p. 264)

A diferença elementar acerca da guarda conjunta e a guarda unilateral está centrada na divisão equânime dos deveres entre os pais dos filhos, fruto da disputa. Essa condição garante aos filhos menores, além de gozarem da companhia de ambos os genitores, em períodos distintos, mas com maior frequência e com o atributo de melhor qualidade destes momentos, que se tornarão parte da rotina destas crianças, e que entenderão à sua condição de dispor de dois lares distintos no qual devem efetivamente ser inseridos.

\begin{abstract}
A guarda compartilhada é aquela em que, alterando-se as relações paternofiliais e materno-filiais, propicia o melhor desenvolvimento psicológico e maior estabilidade para o menor, que não sentirá da mesma forma a perda de referência de seu pai ou de sua mãe, reduzindo-se assim as dificuldades que as crianças normalmente enfrentam $\grave{A}$ nova rotina $\mathrm{e}$ aos novos relacionamentos após a separação dos seus genitores. (AKEL, 2019, p. 43)
\end{abstract}

Em sequência ao tema, é deliberada a guarda compartilha enquanto:

A custódia física, ou custodia partilhada é uma nova forma de família na qual os pais divorciados partilham a educação dos filhos em lares separados. A essência do acordo da guarda compartilhada reflete o compromisso dos pais de manter dois lares para seus filhos e de continuar a cooperar com o outra na tomada de decisões. (GRISARD FILHO, 2016, p. 112)

Há um consenso acerca da corresponsabilidade entre os pais de menores aos serem estabelecida a modalidade da guarda conjunta. Esse intendimento tem facilitado o uso jurídico deste instituto como opção usual, nos casos em que os dois genitores apresentem condições semelhantes para usufruto da guarda.

Compartilhar responsabilidades entre o pai e a mãe, e não imputá-la apensas a uma pessoa, haja vista que a criança e o adolescente necessitam tanto da presença materna quanto paterna, mesmo com a separação e o divórcio de um casal, continua sendo exercido pelo pai e pela mãe. (CASSETARI, 2019, p. 98)

Deste modo a guarda conjunta institui a figura do casal parental, que já não tem laços de conjugalidade, no entanto, estão empossados do poder familiar que lhes conferem decidirem associadamente acerca das melhores condições integrais para a 


\section{Universidade do Extremo Sul Catarinense \\ Revista Ibero-Americana de Humanidades, Ciências e \\ Educação \\ unesc

vida dos filhos frutos do relacionamento desfeito.

A guarda compartilhada inaugura o ideário de um olhar mais democrático sobre o intitulo da família, já que estes dividem equanimemente as responsabilidades sobre a vida dos filhos e vai além, quando se mostra uma opção saudável à guarda unilateral. E permitindo ainda que as condições propícias à alienação parental pereçam já que os pais devem ultrapassar suas mágoas pessoas em nome do bom desenvolvimento integral dos filhos comuns a eles.

\section{PARECER CONCLUSIVO}

Após fazer um breve apanhado histórico acerca da família e as suas transformações sociais a luz dos documentos jurídicos que disciplinavam a vida em sociedade, é possível apostilar que a família sofreu inúmeras mudanças simbólicas que trouxeram novos contornos e formatações familiares.

$\mathrm{Na}$ atualidade o afeto se mostra como um elemento de referência de suma importância para as novas engrenagens familiares, inclusive, se sobrepõe aos laços de consanguinidades. A repersonalização dos laços civis sob a égide da afetividade dá a família, independente da sua formatação, o dever de cuidar e da mutualidade de assistência e dedicação entre os seus membros. E para os pais este dever de cuidar se sobressai diante dos filhos por conta da condição de fragilidade social na qual as crianças menores estão sujeitas.

No entanto, na contramão deste cenário, existe também, nas famílias uma grande desatenção com as responsabilidades inerentes à condição paternal. E um crescente abandono filial, que vai de encontro aos ditames jurídicos, que pregam pelo amparo moral, material e intelectual. Sendo que hoje, o dever de afeto, também é material cobrada nos tribunais.

A constanter inobservância aos enxertos da Constituição e ao Código Civil sobre as responsabilidades dos pais na vida dos infantes, tem chamado o Direito de Família à se posicionarem diante desta querela. E constatado, o incumprimento destes preceitos legais há inúmeras sanções de ordem civil que atinge os pais de acordo com os delitos. Os tribunais em entendimento anterior usavam como penalidade aplicada aos pais ausentes a destituição do poder familiar, no entanto, essa pena se manifestava como uma 


\section{Universidade do Extremo Sul Catarinense \\ Revista Ibero-Americana de Humanidades, Ciências e \\ Educação \\ unesc

'premiação' a sua conduta omissiva diante dos seus filhos, já que deliberadamente s e afastaram do convívio com estes menores.

Além de ineficientes essas penalidades não tinham o caráter educativo, umas das funções implícitas da pena. E concomitantemente, os filhos se viam em situação de alheamento familiar. Já que o genitor acusado do ilícito, usava o argumento da sanção, para justificar a sua completa indiferença frente à vida dos seus filhos. Deste modo, cessava-se por completo a possibilidade de estreitamento afetivo entre pais e filhos.

Sobre a inobservância do direito dos filhos a convivência com seus genitores, há na atualidade um entendimento jurídico a respeito da ilicitude deste ato, inclusive, com sentenciamentos que obrigam o ressarcimento pecuniário diante dos desdobramentos psicológicos ocasionados pelo abandono material dos pais diante dos seus filhos.

O posicionamento inaugural do Superior Tribunal de Justiça acerca do acato de pedido de indenização por danos psicológicos originados do completo abandono material e imaterial, e deve ser comemorado, já que mostra um avanço no trato jurídico quanto o direito dos filhos de conviver com seus progenitores. A convivência gera o estreitamento do elo afetivo como valor jurídico, e como tal deve ser tutelado pelo Estado. A notabilidade jurídica que a afetividade recebeu no lócus jurídico após este julgamento apartou o precedente para novos julgamentos com entendimento semelhante.

Ao compartilhar de posicionamento doutrinário acatado pelo STJ, como operadora do direito, é identificado, também, o cunho educativo que a penalidade exerce sobre o réu, assim, coibir a prática reiterada da inobservância dos direitos dos filhos menores diante do rompimento matrimonial.

O concluso sobre a temática em questão é que é imprescindível uma política que agregue vários setores da sociedade no intuito de trazer a discussão acerca do direito dos filhos menores diante da ruptura familiar. E uma das ferramentas que melhor acolhe essa demanda está amparada pela guarda compartilhada que oferece abrigo às necessidades infantis à convivência com seus genitores que garantam o estreitamento dos laços afetivos respeitando a decisão dos pais em não manterem o matrimônio.

A responsabilidade civil deve ir além do reparo paliativo no que tange o abandono afetivo, e sim, amenizar através da indenização monetária os danos derivados 


\section{Universidade do Extremo Sul Catarinense \\ Revista Ibero-Americana de Humanidades, Ciências e \\ Educação \\ unesc

do desarrimo parental na vida das crianças.

Sem o intuito de esgotar as discussões sobre a temática em voga, mas que se observe e respalde os requisitos mínimos para que haja novos ajuizamentos considerando as demandas reparativas no tocante a ausência afetiva dos pais, e que sejam proferidos sentenciamentos que acolham o entendimento do STJ sobre a indenização compensatória de cunho monetário para os genitores que atente contra o direito protetivo dos seus filhos menores.

Por fim, há uma recomendação aos novos trabalhos que elegerá a temática em questão, para investigar como os tribunais pelo Brasil estão se posicionando após a decisão do STJ em acolher a sanção pecuniária no momento do julgamento do Recurso Especial n. ${ }^{\circ} 1.159 .242$, sob Relatoria da Ministra Nancy Andrighi diante do abandono imaterial do pai da queixosa.

\section{REFERÊNCIAS}

AKEL, Ana Carolina Silveira. Guarda Compartilhada-Uma nova realidade. In: COTRO, Antônio Caros Mathias (coords). Guarda Compartilhada. São Paulo: Editora Método, 2019.

BARBOZA, Heloísa Helena. O princípio do Melhor Interesse a Criança o Adolescente. In: A família na travessia do milênio. Anais do II congresso Brasileiro de Direito de Família (coord. Rodrigo da Cunha Pereira). Belo Horizonte: IBDFAM- Del Rey, 2018.

BRASIL. Lei n.10.406, de 10 de janeiro de 2002. Institui o Código Civil. Brasília: Congresso Nacional, 2002.

Lei Federal $\mathrm{n}^{\circ} 12.010$, de 3 de agosto de 2009. Dispõe sobre adoção; altera as Leis nos 8.069, de 13 de julho de 1990 - Estatuto da Criança e do Adolescente, 8.560, de 29 de dezembro de 1992; revoga dispositivos da Lei no 10.406, de 10 de janeiro de 2002 - Código Civil, e da Consolidação das Leis do Trabalho - CLT, aprovada pelo Decreto-Lei no 5.452,

de 1. ${ }^{\circ}$ de maio de 1943; e dá outras providências. Disponível em: acesso em: 2. Jun.2018.

Lei Federal $\mathrm{n}^{\circ} 11.698$, de 13 de junho de 2008. Altera os arts. 1.583 e 1.584 da Lei no 10.406, de 10 de janeiro de 2002 - Código Civil, para instituir e disciplinar a guarda compartilhada. Disponível em: Acesso em: 12.jun.2018.

Lei Federal $\mathrm{n}^{\circ} 11.340$, de 7 de agosto de 2006. Cria mecanismos para coibir a violência doméstica e familiar contra a mulher, nos termos do $\S 8$ o do art. 226 da Constituição Federal, da Convenção sobre a Eliminação de Todas as Formas de Discriminação contra as Mulheres e da Convenção Interamericana para Prevenir, Punir e Erradicar a Violência contra a Mulher; dispõe sobre a criação dos Juizados de 
Violência Doméstica e Familiar contra a Mulher; altera o Código de Processo Penal, o Código Penal e a Lei de Execução Penal; e dá outras providências. Disponível em: < 10.406, de 10 de janeiro de 2002. Institui o Código Civil. Disponível em: Acesso em: 11. abr. 2018.

Lei Federal no 8.069, de 13 de julho de 1990. Dispõe sobre o Estatuto da Criança e do Adolescente e dá outras providências. Disponível em: Acesso em: 14 abr. 2018.

Constituição (1988). Constituição da República federativa do Brasil de 1988. Disponível em: Acesso em: 18 abr. 2018.

Rel.

Superior Tribunal de Justiça. Recurso Especial no 1.159.242-SP, da $3^{\text {a }}$ Turma.

Min. Nancy Andrighi, julgado em 24/4/2012. Disponível em: Acesso em: 17. Abr. 20 18.

Superior Tribunal de Justiça. Recurso Especial no 450.566, da $3^{\text {a }}$ Turma. Rel. Ministra Nancy Andrighi, julgado em 03/05/2011. Disponível em: Acesso em: 11 abr 2018.

Superior Tribunal de Justiça. Recurso Especial no 709.608, da $4^{\mathrm{a}}$ Turma. Rel. Ministro João Otávio de Noronha, julgado em 05/11/2009. Disponível em: Acesso em: 15 mar. 2018.

Superior Tribunal de Justiça. Recurso Especial $n^{\circ} 878.941$, da $3^{\mathrm{a}}$ Turma. Rel. Ministra Nancy Andrighi, julgado em 21/08/2007. Disponível em: Acesso em: $15 \mathrm{ma}$ r. 2018.

Superior Tribunal de Justiça. Recurso Especial $n^{\circ} 757.411$, da $4^{\mathrm{a}}$ Turma. Rel. Ministro Fernando Gonçalves, julgado em 29/11/2005. Disponível em: Acesso em: 16 mar. 2018.

CAPAO DA CANOA/RS. Processo $n^{\circ}$ 141/1030012032-0. Juiz Mario Romano Maggioni, j.15 de setembro de 2003. Revista Ajuris Sentenças, n.12, Porto Alegre: dezembro de 2004. Disponível em: http://www.ajuris.org.br/revista/revista\%20sentenca\%2002.pdf.pdf. Acesso em 20 mar.2018.

CASSETARI, Christiano. Guarda compartilhada: uma análise da Lei 11.698/2008. In: COLTRO, Antônio Carlos Mathias; DELGADO, Mario Luiz (coords.). Guarda Compartilhada. São Paulo: Editora Método, 2019.

CEZAR-FERREIRA, Verônica A. da Motta. Família, separação e mediação- uma visão psicojurídica. 2. ed. São Paulo: Ed. Método, 2007.

DINIZ, Maria Helena. Curso de direito civil brasileiro: responsabilidade civil. 29. Ed. São Paulo: Editora Saraiva, 2018.

ELIAS, Roberto Joao. Direitos Fundamentos da criança e do adolescente, São Paulo: 
Universidade do Extremo Sul Catarinense

Revista Ibero-Americana de Humanidades, Ciências e

Educação

Unesc Produção e democratização do conhecimento na lbero-América

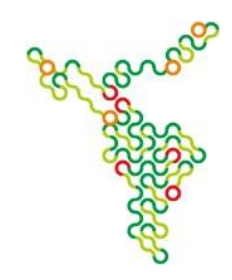

2009.

FERREIRA, A. B. H. Novo dicionário Aurélio da Língua Portuguesa. Rio de Janeiro: Nova Fronteira, 1987.

GOLDSTEIN, Joseph. O melhor interesse a criança. New York: Free Press, 2010.

GRISARD FILHO, Waldyr. Famílias reconstituídas, 2016.

LAURIA, Flávio Guimaraes. A regulamentação e o princípio do melhor interesse da criança. $8^{\text {a }}$ tiragem. Rio de Janeiro: Lumen Juris, 2015.

LEITE, Eduardo de Oliveira. Famílias monoparentais- a situação jurídica de pais e mães separados e dos filhos na ruptura da vida conjugal. $5^{\mathrm{a}}$. ed. Ver. Atual e ampl. São Paulo: RT, 2011.

LÔBO, Paulo Luiz Netto. A família enquanto estrutura de afeto: In: A família além dos mitos (Coords. Eliene Ferreira Bastos, Maria Berenice Dias). Belo Horizonte: Del Rey, 2008.

NASCIMENTO, F. L. do. A transformação do conceito de família no âmbito jurídico. (Salvador: Ucsal, 2018.) (Dissertação/Mestrado) (BDTD).

PEREIRA, Rodrigo da Cunha. Indenização por abandono afetivo e material. In: Revista Brasileira de Direito das Famílias e Sucessões, Porto Alegre: Magister/Belo Horizonte: IBDFAm, v. 28, dez. Jan./2017.

PEREIRA Caio Mario da Silva. Instituições de direito civil: direito de família. 16. Ed. Atual. por Tânia da S. Pereira. Rio de Janeiro: Forense, 2007.

TEIXEIRA, Ana Carolina Brochado. Poder familiar e processo educacional: a polêmica

gradualidade do seu exercício. In: Direito de Família e das sucessões (coords. Gisel da Maria Fernandes N. Hironaka; Flávio Tartuce; José F. Simão). Rio de Janeiro: Forense; São Paulo: Método, 2009.

VELOSO, Zeno. Direito brasileiro da filiação e paternidade. São Paulo: Malheiros, 2017.

VENOSA, Sílvio de Salvo. Direito civil: direito das sucessões. 4. ed. São Paulo: Atlas, 2004.

https://biblioteca.ibge.gov.br/visualizacao/periodicos/135/rc_2016_v43_informativo.pdf Acesso em: 16. abril. 2018.

https://stj.jusbrasil.com.br/jurisprudencia/19484634/recurso-especial-resp- nteiro-teor19484635 . Acesso: 17/abr./2018

https://tj-rs.jusbrasil.com.br/jurisprudencia/211203028/apelacao-civel-ac-70063997167- 
Universidade do Extremo Sul Catarinense

Revista lbero-Americana de Humanidades, Ciências e

Educação

UnesC Produção e democratização do conhecimento na lbero-América

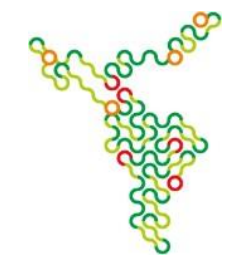

rs/inteiro-teor-211203039?ref=juris-tabs. Acesso: 17/abr./2018.

https://jeffersoncoelho3.jusbrasil.com.br/artigos/129314269/valorizacao-juridica-dafestividade- nas-relacoes-familiares-e-o-reconhecimento-da-responsabilidade-civilextrapatrimonial-por- abandono-afetivo-parento-filial. Acesso: 18/abr/2019. 